In Memoriam

\title{
Angela Biaggio (1940-2003): Um Percurso na História do Desenvolvimento Sócio-Moral do Brasil
}

\author{
Cleonice Camino \\ Universidade Federal da Paraíba ${ }^{1}$
}

Este trabalho apresenta uma visão geral das pesquisas desenvolvidas por Angela Biaggio durante mais de 30 anos, e baseia-se em vários trabalhos da autora, inclusive em uma revisão feita por ela mesma, intitulada "Desenvolvimento Moral: vinte anos de pesquisa no Brasil” (Biaggio, 1988).

Angela Maria Brasil Biaggio nasceu no Rio de Janeiro, em 1940. Fez seu bacharelado em Psicologia na Pontifícia Universidade Católica do Rio de Janeiro (PUC-RJ) e logo em seguida, em 1965, foi fazer seu mestrado na universidade de Wisconsin-Madison nos Estados Unidos, onde também fez, entre 1967 e 1969, sua tese de doutorado.

Biaggio, ao elaborar sua tese de doutorado sob a orientação de Robert E. Grinder, estudou diferentes aspectos do Desenvolvimento Moral: afetivo (culpa), cognitivo (julgamento moral na tipologia de Kohlberg) e comportamentais (resistência à tentação em situações de transgressão). Os resultados principais deste estudo indicaram uma associação positiva entre julgamento moral e índices de culpa internalizada - independente do controle do ego -, e correlação entre a motivação para a aprovação social e a transgressão em situações de competição em que o reconhecimento público estava em jogo.

Em 1969, Angela Biaggio estudou a diferença entre crianças brasileiras e norte-americanas em relação à internalização de culpa e verificou que as crianças norteamericanas internalizavam, significativamente, mais culpa.

A partir de 1969, dedicou-se ao estudo da moralidade na ótica Kohlberguiana. Procurou, sobretudo, investigar a noção de universalidade e seqüencialidade dos estágios morais.

Com este objetivo, Biaggio (1973) realizou uma pesquisa utilizando o MJI - Entrevista do Julgamento Moral, elaborada por Kohlberg - com estudantes universitários norte-americanos e brasileiros. Nos resultados, não encontrou diferenças significativas entre os escores médios dos grupos, mas verificou que os norte-americanos apresentavam, significativamente, mais respostas de um pensamento moral baseado no respeito à autoridade, à lei e à ordem, enquanto os brasileiros apresentavam mais respostas relacionadas à moral do prazer e à moral voltada para o questionamento das leis e para o bem-star social.

\footnotetext{
${ }^{1}$ Endereço para correspondência: Rua da Aurora, 201/908, 58043270 , Miramar, João Pessoa. PB. E-mail: cleocamino@yahoo.com.br

Psicologia: Reflexão e Crítica, 2003, 16(1), pp.1-222
}

Posteriormente, Biaggio (1976) comparou crianças e adolescentes brasileiros com crianças e adolescentes dos Estados Unidos, Formosa e México. Nos resultados, observou muitas semelhanças nas quatro amostras, com exceção do baixo uso do estágio 4 e o alto uso do estágio 3, tanto no Brasil como no México, o que a levou a perguntarse se não havia na cultura latina algo que favorecesse a moralidade da afetividade. Biaggio observou também diferenças entre os sexos: mais alto uso do estágio 3 entre as meninas. Este tipo de dado foi posteriormente analisado por Gilligan (1982) como um viés na teoria de Kohlkerg. Segundo Gilligan, a tipologia de Kolhlberg considerava como mais elevadas as respostas ligadas à lei e à justiça, o que na cultura americana estão mais presentes no sexo masculino, e considerava como menos elevadas respostas ligadas à moral do cuidado, que seriam as respostas mais dadas pelo sexo feminino. Para Angela Biaggio, apesar das diferenças encontradas em seus estudos, os resultados, em geral, confirmam a idéia de universalidade e seqüencialidade.

Em seguida a esses estudos, Angela Biaggio (1979) passou a interessar-se pela verificação de fatores intrínsecos e extrínsecos que pudessem afetar o desenvolvimento moral. Entre os fatores externos ela estudou as atitudes maternas de controle, o tipo de escola e a influência de colega; como fatores intrínsecos, analisou a influência da estrutura da personalidade, do locus de controle e da ansiedade no julgamento moral. Neste sentido, vários trabalhos foram desenvolvidos por Angela juntamente com orientandos de pós-graduação.

Em um dos estudos (Biaggio, 1979), adolescentes e universitários responderam ao MJI e a questionários sobre percepção de atitudes maternas e de colegas. Os resultados, em geral, sugeriram que, para os adolescentes brasileiros, as influências dos companheiros eram mais fortes do que as influências maternas. As únicas variáveis maternas que correlacionaram significativamente, embora de forma negativa, com os escores de maturidade moral foram a severidade e o desligamento hostil da mãe (no caso dos adolescentes), indicando que mães com este perfil podem retardar o desenvolvimento da estrutura moral no caso de seus filhos.

Gerbase (1984), sob orientação de Angela Biaggio, realizou uma pesquisa utilizando o Defining Issues Test DIT - com adolescentes de uma escola liberal e de uma escola tradicional, e constatou uma maior incidência do estágio 6 nos alunos da escola liberal. 
A preocupação de explorar um pouco mais a diferença de sexo, ou provavelmente de gênero, levou Koller (1990), em dissertação orientada por Biaggio, a estudar a influência do gênero no julgamento moral. Para tanto, Koller utilizou um delineamento experimental bastante complexo e realizou uma pesquisa com 306 estudantes universitários que responderam a um questionário de tipificação sexual e ao MJI. Os resultados indicaram que os andróginos apresentavam os níveis mais elevados de julgamento moral, seguidos pelos sujeitos tipificados sexualmente, e, finalmente os julgamentos morais menos elevados foram dos indiferentes. Enfim, esse trabalho mostrou uma influência grande do fator socialização sexual em relação ao julgamento moral.

Dentro do estudo da relação entre a moral e diferentes variáveis intrapsíquicas, há também o de Biaggio e Spada (1982), realizado com uma amostra de 100 estudantes universitários. Estes estudantes responderam à escala de Atitudes Éticas de Hogan (1970, 1975, citado em Biaggio, 1988) e às Escala de Personalidade de Comrey (1973, citado em Biaggio, 1988). Nos resultados, dentre outros, foi observada uma correlação positiva entre ética da responsabilidade social e as escalas de conformismo versus rebeldia e ordem versus falta de compulsão, das quais valem os primeiros pólos de cada uma.

Ainda dentro desse enfoque, Biaggio e Guazzelli (1984) investigaram a relação entre maturidade de julgamento moral e internalização de locus de controle. Foi encontrada uma relação positiva com alunos de pósgraduação mas não com alunos de graduação. Os autores atribuíram a correlação encontrada a uma maior variação de escores nos alunos de pós-graduação.

A partir de 1983, Angela Biaggio voltou-se, sobretudo, para os trabalhos de intervenção. Com base nos resultados de Blatt e Kohlberg (1975), iniciou atividades com vistas à promoção de julgamento moral. Este trabalho supõe que, sendo gerado um conflito cognitivo entre os participantes de um grupo - a partir de suas distintas posições a respeito de um dilema moral - , a busca de uma solução para o conflito faria com que os participantes que tivessem argumentos menos avançados, ao se depararem com argumentos mais avançados, mudariam seus argumentos por argumentos mais avançados. Isto é, os sujeitos em conflito sempre prefeririam argumentos que estivessem acima dos seus.

Continuando interessada em verificar a relação entre julgamento moral e variáveis intrapsíquicas, Biaggio (1989) realizou um estudo experimental em que utilizou uma dinâmica de grupo e fez avaliações - pré-teste e pósteste - a ansiedade dos participantes. Para a avaliação da ansiedade, Biaggio utilizou o Inventário de Ansiedade
Traço-Estado de Spielberger (Biaggio, Natalício \& Spielberger, 1977). Nos resultados do pós-teste constatou que houve um aumento de ansiedade, que ela atribuiu às discussões morais em grupo. Um outro resultado que ela constatou, foi uma correlação negativa entre traço de ansiedade e a maturidade de julgamento moral para sujeitos do sexo masculino. É importante ressaltar a relevância da relação que Biaggio estabeleceu entre ansiedade e moral diante do fato de que aqueles que trabalharam com a teoria de Kohlberg pouco ou nada verificaram os aspectos emocionais da questão. Pode-se até dizer que o próprio Kohlberg não deu a devida importância ao estudo da afetividade em seu trabalho.

Biaggio (1983, citado em Biaggio, 1988) efetuou um trabalho de intervenção com orientandos e educadores de um colégio de Porto Alegre. Após realizar pré e pós-testes, verificou que os participantes do grupo tiveram ganhos em maturidade de julgamento. Em seguida, outros trabalhos foram realizados por orientandos que participaram da intervenção anterior. Um realizado com 33 alunos de $7^{\mathrm{a}}$ série, em que os dados do pós-teste em comparação com o pré-teste revelaram um escore médio de julgamento moral significativamente mais alto do que no pré-teste, e outro realizado com alunos de oitava série de uma escola pública, utilizando um grupo de controle, em que os resultados demonstraram aumento nos dois grupos.

De uma forma geral, estas experiências indicaram a Biaggio a necessidade do experimentador e coordenador do grupo trabalhar com dilemas que fossem elaborados pelos próprios alunos. A autora interpretou essa exigência como relacionada à baixa incidência do estágio 4 (lei e ordem) entre os brasileiros - um certo inconformismo para com a autoridade.

Outros trabalhos de intervenção continuaram a ser realizados durante as décadas de 1980 e 1990, período no qual se insere o trabalho realizado por Jussará Lummertz (1991), orientanda de doutorado de Angela Biaggio. Lummertz trabalhou com 30 adolescentes do sexo masculino, utilizando o método de discurso de Berkowitz (1982, citado em Lummertz, 1991): a discussão de dilemas através de duplas. Os resultados mostraram a importância da intervenção.

Outras intervenções foram realizadas por Biaggio com alunos de pedagogia com a finalidade não só de melhorar seu nível de maturidade moral, mas para que eles pudessem, no futuro, utilizar a técnica com seus alunos.

Em trabalhos de natureza teórica, Biaggio e Morosini (1987) e Morosini e Biaggio (1985) também discutiram a relação entre o pensamento pós-convencional e a possibilidade de transgressão social, considerando o papel da escola na transformação social. 
Um trabalho digno de nota foi a tentativa de Biaggio (1997) de implantar uma comunidade justa. Após seu pós-doutorado, em 1994, período em que trabalhou com Clark Power sobre comunidades justas, Biaggio iniciou um programa para a implantação de uma comunidade justa em uma escola pública de Porto Alegre. Para tanto, realizou palestras e discussões sobre a teoria de Kohlberg envolvendo professores, coordenação e a direção da escola. Essas discussões, porém, segundo a própria autora, não foram bem sucedidas, pois os professores faltaram muito, por trabalharem em outras escolas, e, além disso, ocorreu uma paralisação durante a primeira fase da pesquisa. Em uma segunda fase desse programa, dois psicólogos que cooperaram com Biaggio discutiram com alunos da $8^{\mathrm{a}}$ série dilemas que versavam sobre conteúdos ecológicos e não-violência. Entretanto, a realização dessa atividade foi interrompida por uma mudança de coordenação na escola. Apesar disso, a análise das discussões levou Biaggio a julgar que houve algum avanço na concepção de justiça dos estudantes.

Em 1996, Biaggio realizou a discussão de dilemas ecológicos com universitários do curso de psicologia, procurando capacitá-los para trabalhos de intervenção na área das cognições sócio-morais.

Biaggio (1999) realizou uma pesquisa para compreender as atitudes das pessoas para com o meio ambiente. Esta pesquisa envolveu 108 universitários de cinco países: Brasil, Chile, Portugal, Alemanha e Estados Unidos. Os universitários responderam a um questionário com itens abertos e fechados. Após uma análise de conteúdo, a autora verificou que, dentre outros resultados, as respostas de portugueses e chilenos foram as mais elaboradas e as que mais continham sugestões sobre como lidar com os problemas de meio ambiente; a dos brasileiros foram as que mais sugeriram atividades práticas; as dos alemães foram as que mais revelaram o pessimismo. Os estudantes dos Estados Unidos apresentam-se como os mais tolerantes com os pesticidas e com o uso da energia nuclear.

Um outro foco de atenção de Biaggio foi o problema da paz no mundo. Neste sentido, Biaggio e Sousa (material não-publicado) investigaram as atitudes de brasileiros para a paz, guerra e violência. As autoras compararam as atitudes referentes à paz, à guerra e à violência em cinco cidades brasileiras de quatro áreas geográficas distintas: Belo Horizonte; (Sudeste); Niterói (Sudeste); Rio de Janeiro (Sudeste); João Pessoa (Nordeste); Manaus (Norte); Porto Alegre (Sul). O estudo procurou investigar a violência em três níveis: mundialmente (guerras), nacionalmente (violência urbana) e individualmente.

Em uma pesquisa transcultural, Biaggio e Sousa (material não-publicado) também verificaram as atitudes em relação à paz de 171 estudantes, de dois níveis de escolaridade, provenientes do Brasil, Chile, Portugal, Alemanha e Estados Unidos. Os estudantes responderam a um questionário de 11 questões abertas. Após análise de conteúdo, os autores verificaram categorias comuns aos cinco países e categorias que diferenciam os países. Ainda nos resultados desta pesquisa podem ser constatadas diferenças em relação ao grau de escolaridade.

O conjunto da obra e do trabalho de Angela Biaggio - que foi aqui muito brevemente descrito - revela algumas características das preocupações intelectuais e humanas da autora que convém resgatar.

Do ponto de vista do desenvolvimento sócio-moral, pode-se perceber uma inicial abordagem do desenvolvimento sócio-moral individual, que posteriormente dirige-se para o desenvolvimento sócio-moral nas relações interpessoais e, finalmente, preocupa-se com o desenvolvimento de atitudes morais e éticas, isto é, com a forma da humanidade lidar com questões do meio ambiente e construir a paz no mundo.

Concernente à dinâmica e à estrutura do fenômeno 'desenvolvimento moral', pode-se perceber uma fase inicial cuja preocupação consiste em verificar os elementos constitutivos da moral, em seguida, em verificar fatores intrapsíquicos e extrínsecos (família, escola, colegas) que poderiam estar associados a este desenvolvimento e, posteriormente, uma preocupação em realizar trabalhos que promovessem o desenvolvimento sócio-moral e ético. Estas fases não se sucedem necessariamente, entretanto, observa-se uma forte tendência das primeiras pesquisas investigarem pressupostos teóricos e as últimas estarem mais ligadas a trabalhos de intervenção.

Ao analisar o trabalho de Angela Biaggio, um outro aspecto que chama a atenção é o fato dela apresentar uma preocupação constante em verificar o que existe de universal e de relativo na forma das pessoas pensarem sobre a moral, a paz, a violência e o meio ambiente, uma inquietação que se traduz através das várias pesquisas transculturais realizadas ao longo de sua trajetória como pesquisadora.

Nota-se também que, apesar do enfoque dominante que embasou as pesquisas de Biaggio ter sido o Kohlberguiano, em vários trabalhos empíricos ela articulou o construtivismo com outros enfoques teóricos, principalmente o behaviorismo.

Toda essa atividade mostra a crença de Biaggio na mudança e a vontade de contribuir para transformação da realidade social. Mostra também o quanto ela foi responsável pela difusão do pensamento de Kohlberg no Brasil. Demonstra a riqueza de todo um instrumental de diagnóstico e de intervenção que hora foi adaptado, ora foi construído pela autora e seus colaboradores, e a imensa riqueza de dados de pesquisas. 


\section{Referências}

Biaggio, A. (1973). Uma comparação transcultural de estudantes universitários brasileiros e norte-americanos na medida de julgamento moral de Kohlberg. Arquivos Brasileiros de Psicologia Aplicada, 27, 71-81.

Biaggio, A. (1976). A developmental study of moral judgment of Brazilian children and adolescents. Interamerican Journal of Psychology, 10, 71-81.

Biaggio, A. (1979). Maternal and peer correlates of moral judgement. Journal of Genetic Psychology, 135, 203-208.

Biaggio, A. (1988). Desenvolvimento moral: Vinte anos de pesquisa no Brasil. Psicologia: Reflexão e Crítica, 1, 60-69.

Biaggio, A. (1989). Relações entre maturidade de julgamento moral e ansiedade traço-estado. Arquivos Brasileiros de Psicologia, 41, 9-22.

Biaggio, A. (1997). Kohlberg e a comunidade justa: Desenvolvendo o senso ético e a cidadania na escola. Psicologia: Reflexão e Crítica, 10, $47-$ 69.

Biaggio, A. (1999). Desenvolvimento moral, ecologia e pacifismo. (Simpósio). AME (Association for Moral Education), Minneapolis, Minn.

Biaggio, A. \& Guazzelli, E. F. (1984). Relações entre maturidade de julgamento moral e locus de controle. Arquivos Brasileiros de Psicologia Aplicada, 36, 63-73.

Biaggio, A., Natalício, L. \& Spielberger, C. D. (1977). Desenvolvimento da forma experimental em Português do Inventário de Ansiedade TraçoEstado de Spielberger. Arquivos Brasileiros de Psicologia Aplicada, 29, 31 44.
Biaggio, A. \& Morosine, M. (1987). Reprodución, Resitencia y pensamiento posconvencional; una comparación entre las teorias de Kohlberg y Giroux con respecto al papel de la escuela en la trasnfomación de la sociedad. Boletin de Psicologia (Universidad José Cañas, El Salvador).

Biaggio, A. \& Spada, M. (1982). Relationsship between maturity of moral judgment and the structure of personality: A test of Hogan's hypothesis with Brazilian subjects. Interamerican Journal of Psychology, $16,23-30$

Blatt, M. M. \& Kohlberg, L. (1975). The effects of classroom moral discussion upon children's level of moral judgment. Journal of Moral Education, 4, 129-161.

Gerbase, C. K. (1984). Relações entre maturidade de julgamento moral e atitudes de pais, colegas e filosofia da escola. Dissertação de Mestrado não-publicada, Curso de Pós-Gradução em Psicologia do Desenvolvimento, Universidade Federal do Rio Grande do Sul. Porto Alegre, RS.

Gilligan, C. (1982). Uma voz diferente. Rio de Janeiro: Rosa dos Tempos.

Koller, S. (1990). Diferença de gênero no julgamento moral. Dissertação de Mestrado não-publicada, Curso de Pós-graduação em Psicologia do Desenvolvimento, Universidade Federal do Rio Grande do Sul. Porto Alegre, RS.

Lummertz, J. G. (1991). Pensamento crítico e mudança social: A utilização de interações dialógicas no desenvolvimento do julgamento moral. Tese de Doutorado não publicada, Curso de Pós-graduação em Educação, Universidade Federal do Rio Grande do Sul. Porto Alegre, RS.

Morosini, M. \& Biaggio, A. (1985). O resgate do sujeito na transformação social. Psicologia Reflexão e Crítica, 1, 1-21. 